九州大学学術情報リポジトリ

Kyushu University Institutional Repository

\title{
Effect of Neutral Salt on the Formation of Lysozyme-Substrate Complex
}

Hayashi, Katsuya

Laboratory of Sericultnral Chemistry, Faculty of Agriculture, Kyushu University

Hamasu, Yasuhisa

Doi, Yasutaka

Funatsu, Masaru

Laboratory of Biochemistry, Faculty of Agriculture, Kyushu University

https://doi.org/10.5109/22841

出版情報：九州大学大学院農学研究院紀要. 17 (3/4)，pp.327-337，1973-10. Kyushu University バージョン：

権利関係 : 


\title{
Effect of Neutral Salt on the Formation of Lysozyme-Substrate Complex
}

\author{
Katsuya Hayashi, Yasuhisa Hamasu*, Yasutaka Doi** and \\ Masaru Funatsu \\ Laboratory of Sericultnral Chemistry and Laboratory of Biochemistry, \\ Faculty of Agriculture, Kyushu University, Fukuoka
}

(Received July 10, 1973)

\begin{abstract}
The effects of sodium chloride concentration on the formation of the lysozyme-substrate complex in solution and on the adsorption of lysozyme on chitin column were examined. The presence of sodium chloride enhanced the formation of complexes with various substrates, hence increased the value of equilibrium constant in the system consisted of free enzyme, free substrate and complex. In ordinary buffer solution such as $0.1 \mathrm{M}$ acetate buffer, lysozyme was not adsorbed on chitin column in the $\mathrm{pH}$ region below 3. The presence of sodium chloride increased profoundly the adsorption of lysozyme on chitin column in this $\mathrm{pH}$ region.
\end{abstract}

\section{INTRODUCTION}

It has been reported that neutral salts enhanced the formation of lysozymesubstrate complex in solution and the adsorption of lysozyme on an insoluble carboxymethyl chitin, although the hydrolytic and transglycosylation activities of lysozyme were remarkably inhibited by the presence of neutral salts such as sodium chloride (Imoto et al., 1968; Imoto et al., 1969). This fact suggested that the lysozyme-substrate complex in the presence of sodium chloride (above 0.2 M) was nonproductive in nature and may be different from those formed in the absence of an extra sodium chloride.

Generally, it was frequently observed that an enzymatic activity was delicately affected by the presence of neutral salts or by the high ionic strength of the medium. The generalized mechanism by which the effect of neutral salts results in is not yet demonstrated.

On the other hand, it has been well known that the equilibrium (association) constant for an enzyme-substrate complex formation depends upon various factors such as the composition of medium, presence of additive, modification of enzyme or structure of substrate. The equilibrium constant is the ratio of the rate constants of forward reaction $k_{1}$ to that of reverse reaction $k_{2}$ in an equilibrium system. Therefore, the change in the equilibrium constant is due to the change in the rate constants in equilibrium system. However, the estimation of the rate constants in an equilibrium system was thought to be very difficult,

\footnotetext{
* Nihon Shinyaku Co. Ltd., Kyoto.

** Kojin Co. Ltd., Tokyo.
} 
because the forward and reverse reactions are usually of very rapid. Consequently, the change in the absolute value of the rate constants accompanying the change in the equilibrium constant has not yet been estimated for general cases.

The values of equilibrium constants for the enzyme-substrate complex formation have been measured for many enzyme systems. It is very likely that for the quantitative description of enzymatic reaction, the rate constants of equilibrium system should be exactly estimated under various conditions. In this connection, the authors intended to estimate the real changes in the reaction rate constants for lysozyme-substrate complex formation accompanied by the changes in circumstantial conditions, in the hope of obtaining some information on the mechanism of lysozyme catalysis. Before that, it seems to be absolutely necessary to study the change in the circumstantial conditions including the addition of sodium chloride as a neutral salt to the lysozyme-substrate system.

The present paper deals mainly with the experiments on the effect of sodium chloride on the lysozyme-substrate complex formation.

\section{EXPERIMENTAL}

\section{Materials}

Lysozyme, glycol chitin, carboxymethyl chitin, partially deacetylated chitin and partially hydrolyzed substrates were prepared according to the methods reported in previous papers (Imoto et al., 1963; Hayashi et al., 1969). Chitin powder was prepared from purified chitin from shrimp shell by grinding it with a ballmill to below 200 mesh.

\section{Methods}

The amount of lysozyme-substrate complex in solution was determined by difference spectrophotometry (Hayashi et al., 1964).

Effect of sodium chloride: Substrate solution at varied concentration was mixed with equal volume of $0.2 \%$ lysozyme solution and the optical density at $293 \mathrm{~nm}$ in the difference spectrum, $\Delta \mathrm{OD}_{293}$ was measured. A suitable substrate concentration, which gave about half of the maximum $\Delta \mathrm{OD}_{293}$ value was chosen and used for the experiments on the effect of sodium chloride. The concentrations thus determined were distributed in the range from 0.01 to $0.04 \%$, depending upon the sort of the substrate. To the mixture containing $0.1 \%$ lysozyme and substrate at suitable concentration was added sodium chloride to desired concentration, and the $\triangle \mathrm{OD}_{293}$ was measured. The effect of sodium chloride was represented by $\Delta\left(\Delta \mathrm{OD}_{293}\right)$, which was calculated by subtracting the value of $\Delta \mathrm{OD}_{293}$ of the mixture not containing sodium chloride from that of the mixture containing sodium chloride at fixed concentration.

Adsorption on chitin column: After washing with $0.5 \mathrm{~N}$ sodium hydroxide and $0.5 \mathrm{~N}$ hydrochloric acid and water successively, the chitin powder (about $1.0 \mathrm{~g})$ was packed in a column $(1 \times 10 \mathrm{~cm})$ and the column was washed with a desired buffer solution. A large excess of lysozyme solution was applied onto 
the column and the column was washed with the same buffer solution until no $\mathrm{OD}_{280}$ was detected in washed medium. Then the adsorbed lysozyme was eluted by $0.2 \mathrm{~N}$ acetic acid and the amount of lysozyme was calculated from the total $\mathrm{OD}_{280}$ using $\mathrm{E}_{1 \mathrm{~cm}}^{0.1 \%}=2.69$ (Imai et al., 1963).

\section{RESULTS}

\section{Change in amount of the complex with substrate concentration}

It is necessary to choose a suitable concentration of substrate for demonstrating the effect of sodium chloride, so that it gives the half of maximum $\Delta \mathrm{OD}_{293}$ value which was observable when a large excess of substrate was used. For this purpose, $\triangle \mathrm{OD}_{293}$ was measured with changing the substrate concentration under the fixed concentration of lysozyme (final concentration: $0.1 \%$ ). An example is shown in Fig. 1. In the case of partially hydrolyzed glycol chitin, the

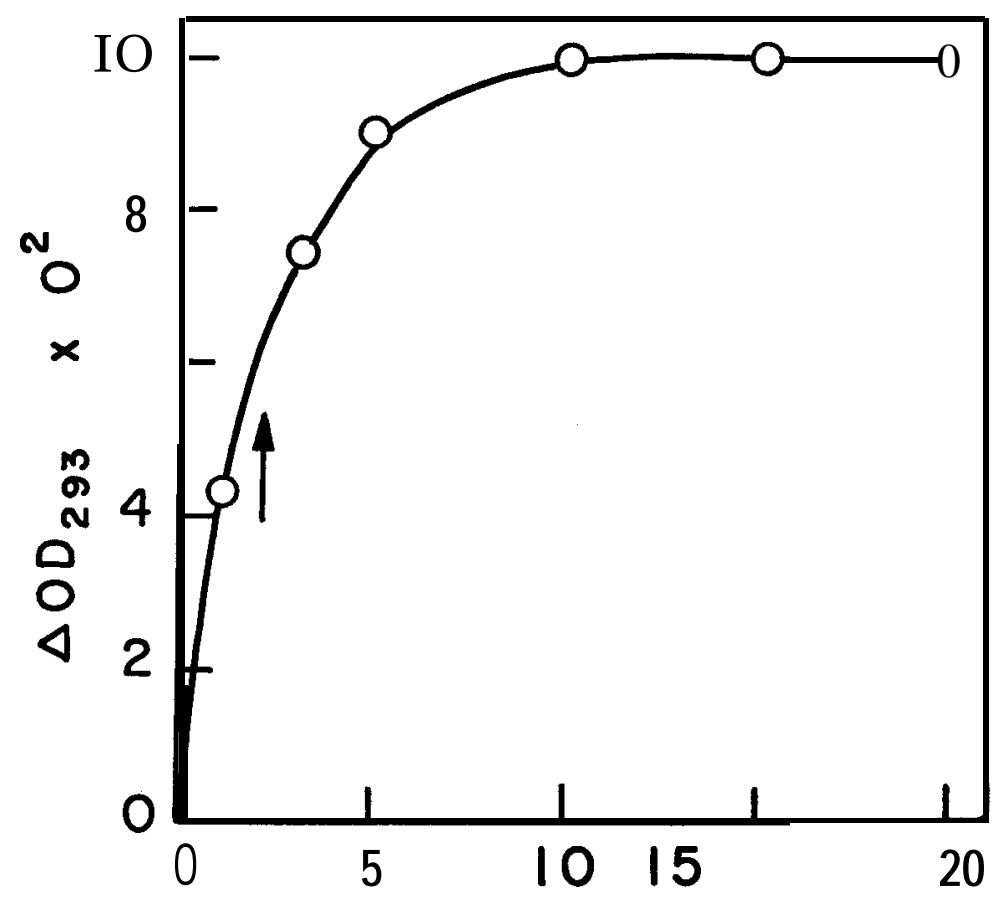

\section{CONCENTRATION OF SUBSTRATE $\times 10^{2}(\mathrm{M})$}

Fig. 1. Effect of substrate concentration on formation of lysozyme-substrate complex. Concentration of lysozyme was $0.1 \%$ and partially hydrolyzed glycol chitin was used as substrate. 0.1 M Acetate buffer solution, pH 5.0 was used. Arrow indicates the concentration used for the experiment on the effect of sodium chloride. 
maximum $\triangle \mathrm{OD}_{293}(0.10)$ was observed at the substrate concentration above 0.1 $\%$. The concentration which gave the half of the maximum $\Delta \mathrm{OD}_{293}$ was about $0.02 \%$. Thus, the concentration of $0.02 \%$ of partially hydrolyzed glycol chitin was used for estimation of the effect of sodium chloride. Suitable concentrations of carboxymethyl chitin and partially deacetylated chitin were found to be 0.01 and $0.04 \%$ respectively.

\section{Effect of sodium chloride on complex formation with partially hydrolyzed glycol chitin}

The sodium chloride concentration which was required for bringing up the $\Delta\left(\Delta \mathrm{OD}_{293}\right)$ to the saturated (maximum) value depended upon the $\mathrm{pH}$ value of medium used, and $0.3 \mathrm{M}$ and $0.5 \mathrm{M}$ were required at $\mathrm{pHs} 5$ and 3 , respectively as shown Fig. 2. The saturated value of $\boldsymbol{\Delta}\left(\Delta \mathrm{OD}_{293}\right)$ were 0.03 at $\mathrm{pH} 3$ and 0.022 at $\mathrm{pH} 5$. The maximum value of $\Delta \mathrm{OD}_{293}$ in the absence of sodium chloride were 0.042 at $\mathrm{pH} 3$ and 0.053 at $\mathrm{pH}$. Therefore, the absolute value of $\triangle \mathrm{OD}_{293}$ in the presence of enough amount of sodium chloride were $0.042+0.03=0.072$ at $\mathrm{pH} 3$ and $0.053+0.022=0.075$ at $\mathrm{pH} 5$. These values are thought to be the same within the experimental error. This will be discussed later.

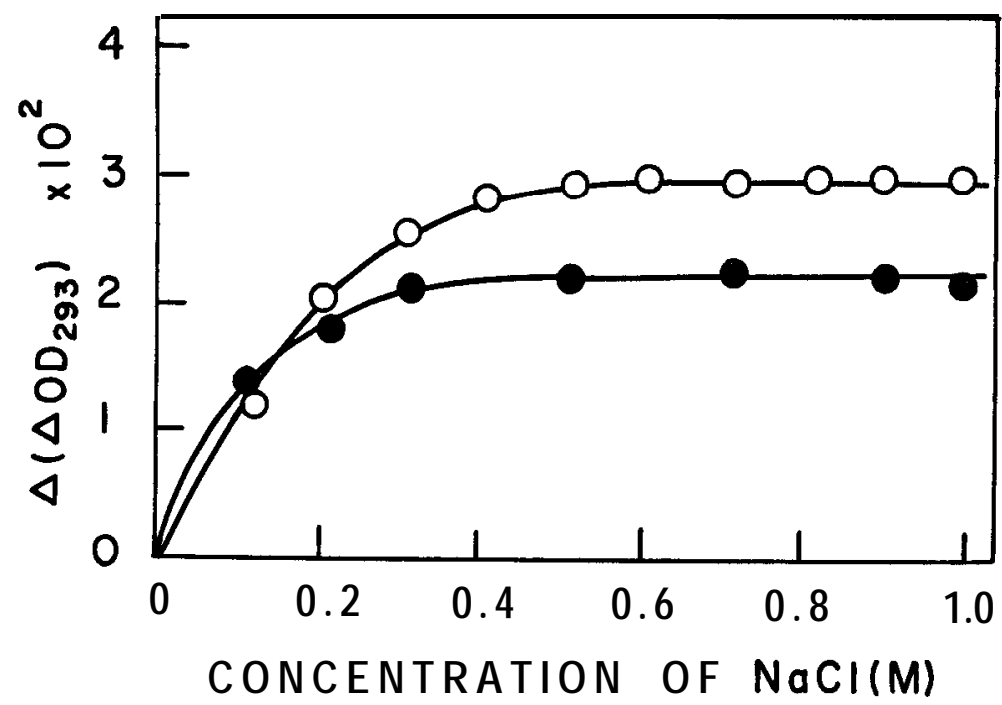

Fig. 2. Effect of sodium chloride on formation of lysozyme-substrate complex. Concentration of lysozyme was $0.1 \%$ and partially hydrolyzed glycol chitin was $0.023 \%$. - :0.1M Acetate buffer at $\mathrm{pH} 3.0$ and $\mathrm{O}: 0.1 \mathrm{M}$ acetate buffer at $\mathrm{pH} 5.0$.

\section{Effect of sodium chloride on complex formation with carboxymethyl chitin}

The effect of sodium chloride on the complex formation with carboxymeth, . chitin was quite a chracteristic; the saturation value of $\Delta\left(\Delta \mathrm{OD}_{293}\right)$ was 0.025 and it was brought about by very low concnetration $(0.1 \mathrm{M})$ of sodium chloride at $\mathrm{pH} 5$ as shown in Fig. 3. 


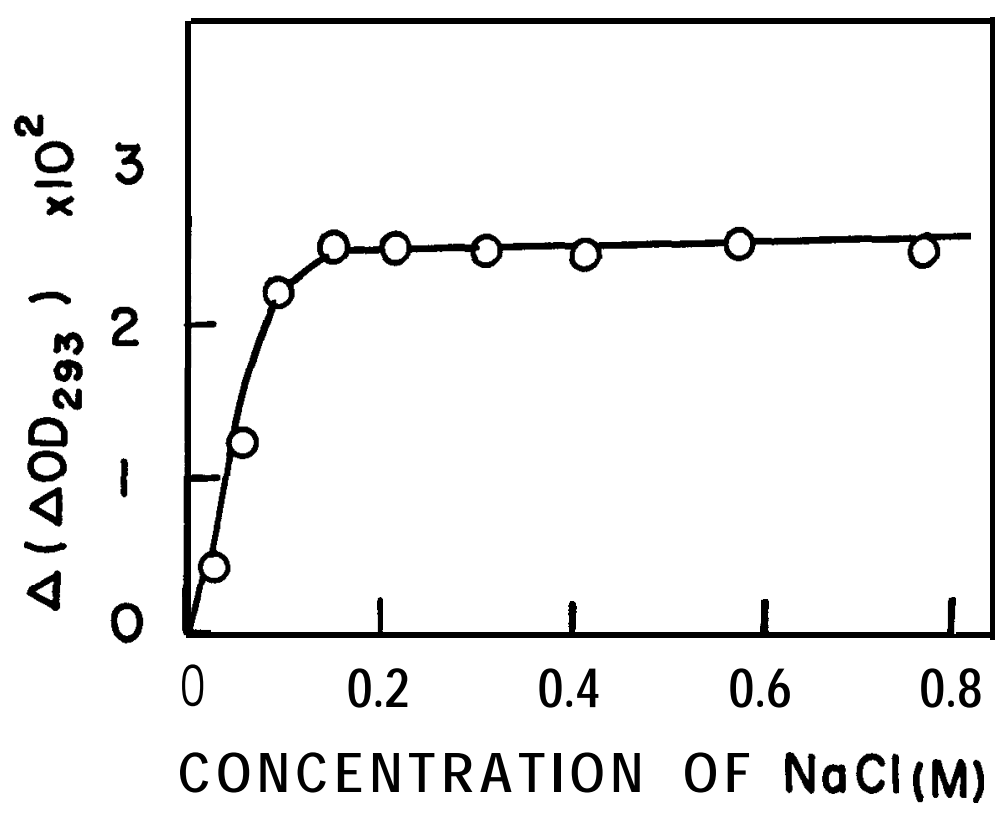

Fig. 3. Effect of sodium chlorlide on formation of lysozyme-substrate complex with carboxymethyl chitin as substrate. Concentrations of lysozyme and substrate were 0.1 and $0.01 \%$, respectively. Buffer solution was $0.1 \mathrm{M}$ acetate at $\mathrm{pH} 4.5$.

\section{Effect of sodium chloride on complex formation with partially deacetylated chitin}

In this case, the saturation value of $\Delta\left(\Delta \mathrm{OD}_{293}\right)$ was found to be 0.05 (Fig. 4), whereas the $\Delta \mathrm{OD}_{293}$ value in the absence of sodium chloride was considerably low as 0.02. These data are summarized in Table 1.

Table 1. Effect of sodium chloride on formation of lysozyme-substrate complex.

\begin{tabular}{l|c|c|c|c}
\hline \multicolumn{1}{c|}{ Substrate } & Conc. $(\%)$ & $\mathrm{pH}$ & $\Delta\left(\Delta \mathrm{OD} \mathrm{D}_{293}\right)_{\max }^{*}$ & $\begin{array}{l}\mathrm{NaCl} \mathrm{conc.} \\
\text { for } \Delta\left(\Delta \mathrm{OD}_{293}\right)_{\max } \\
(\mathrm{M})\end{array}$ \\
\hline Hydrolyzed glycol chitin & 0.023 & 5.0 & 0.022 & 0.3 \\
Hydrolyzed glycol chitin & 0.023 & 3.0 & 0.030 & 0.5 \\
Carboxymethyl chitin & 0.010 & 4.5 & 0.025 & 0.1 \\
Chitosan** & 0.040 & 4.0 & 0.052 & 0.2 \\
Hydrolyzed chitosnn & 0.040 & 4.5 & 0.050 & 0.5 \\
\hline
\end{tabular}

* Saturated value of $\Delta\left(\Delta \mathrm{OD}_{293}\right)$.

** Partially deacetylated chitin.

\section{pH-Dependence of complex formation}

Since the effect of sodium chloride on the complex formation was pH-dependent and a considerably low concentration of sodium chloride brought about a large value of $\Delta\left(\Delta \mathrm{OD}_{293}\right)$, the pa-dependence of the complex formation in usual buffer 


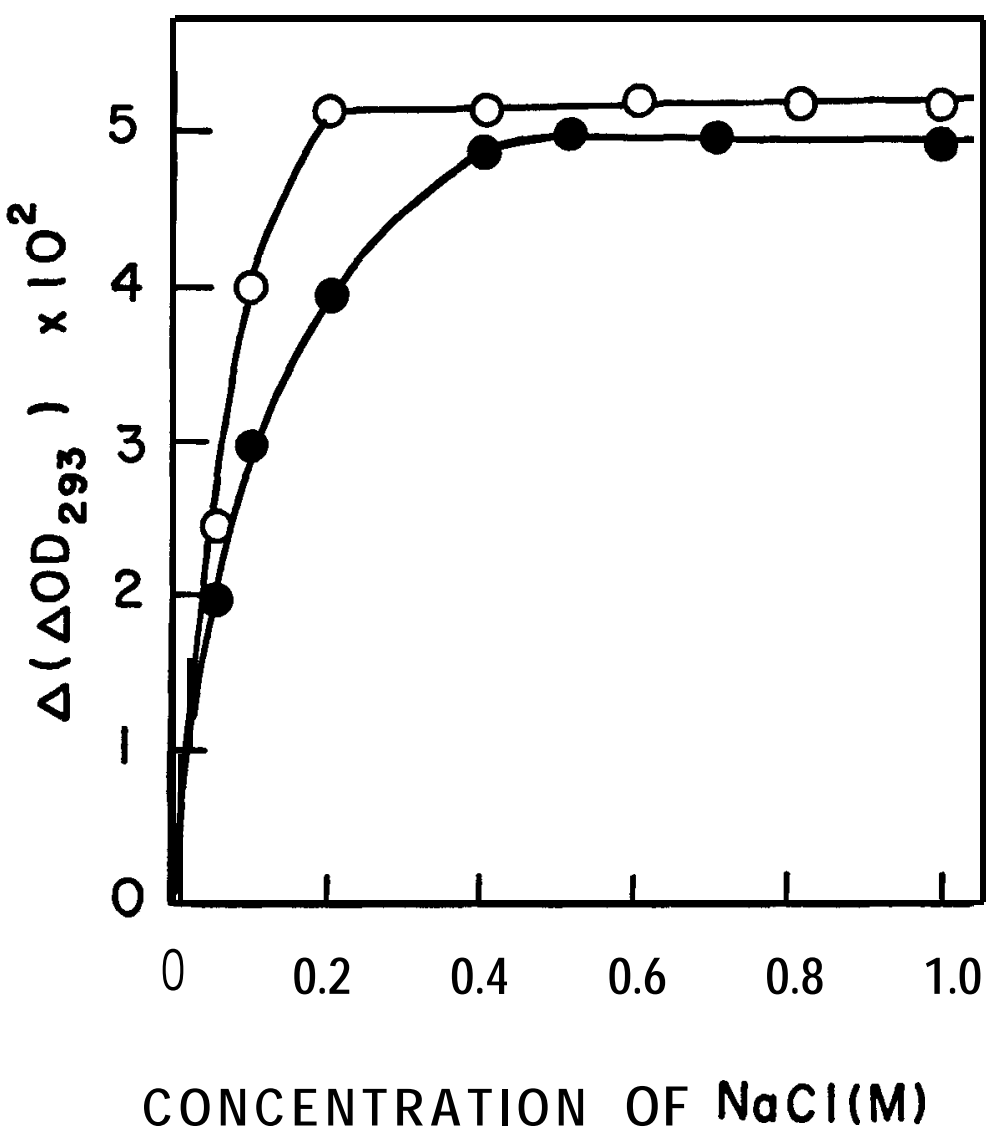

Fig. 4. Effect of sodium chloride on formation of lysozyme-substrate complex. $\bigcirc$ : $0.04 \%$ Partially deacetylated chitin in $0.1 \mathrm{M}$ acetate buffer at $\mathrm{pH} 4.0$ and $\bullet: 0.04$ $\%$ partially deacetylated chitin which was hydrolyzed previously by lysozyme, in 0.1 $\mathrm{M}$ acetate buffer at $\mathrm{pH} 4.5$.

solution should be determined by means of the constant ionic strength buffer system. Fig. 5 shows the $\mathrm{pH}$-dependence of the complex formation between lysozyme and partially hydrolyzed glycol chitin with or without buffer solutions of constant ionic strength. The gross profile is not so much different from each other, but the constant ionic strength buffer solution gave an appreciably flat profile. Fig. 6 shows the effect of the polymerization degree of the substrate. Except for alkaline region, the pa-dependence of polymer substrate was quite similar to that of oligomer substrate (Hamaguchi and Hayashi, 1972).

\section{Effect of sodium chloride on adsorption on chitin column}

Lysozyme was scarcely adsorbed on the chitin coulmn in $0.1 \mathrm{M}$ acetate buffer solution at $\mathrm{pH}$ 4.0. The addition of sodium chloride to this buffer solution increased the adsorbed amount of lysozyme on the column. Up to $0.3 \mathrm{M}$, the so- 


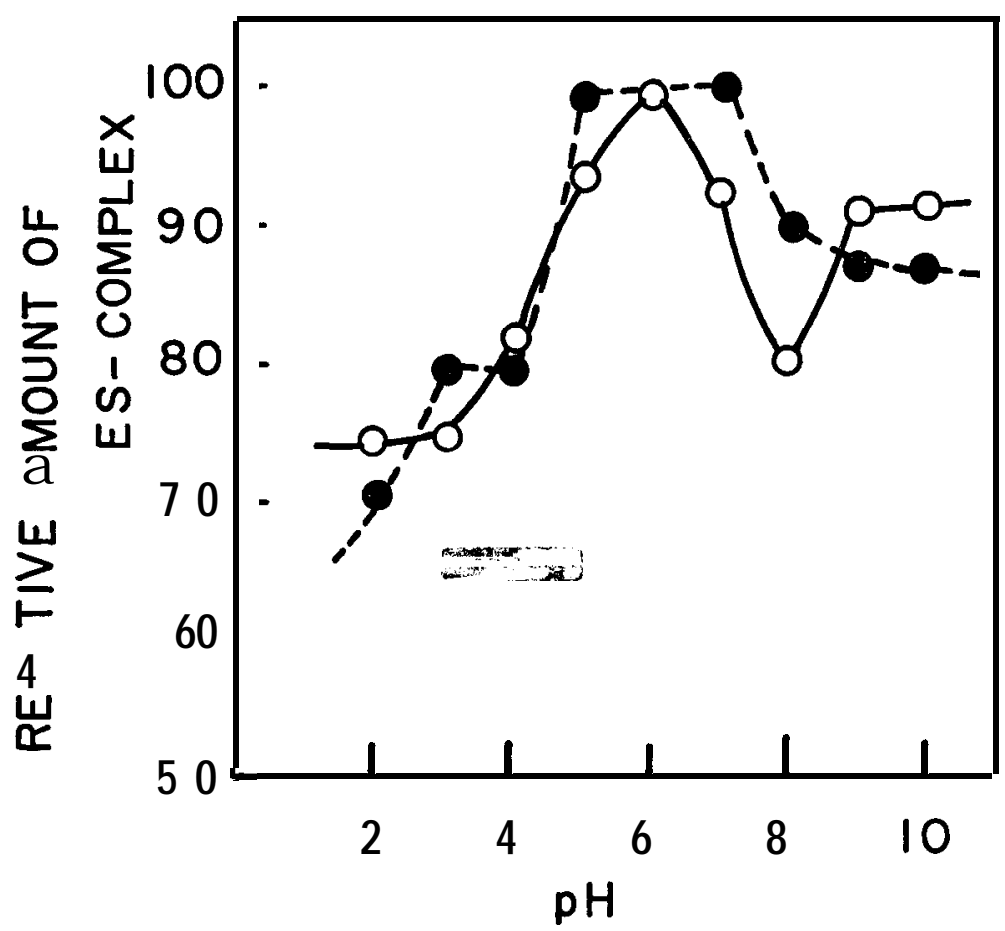

Fig. 5. pH-Dependence of formation of lysozyme-substrate complex. $\bigcirc: 0.1 \mathrm{M}$ Buffer solutions and : buffer solution with constant ionic strength of 0.1. Concentration of lysozyme and substrate was $0.1 \%$. respectively.

dium chloride increased linearly the adsorbed amount and above $\mathbf{0 . 3} \mathrm{M}$ no further increase was observed (Fig. 7). At pH 8.0, a considerably large amount of lysozyme ( $2 \mathrm{mg} / \mathrm{g}$ chitin) was adsorbed on the chitin column. The addition

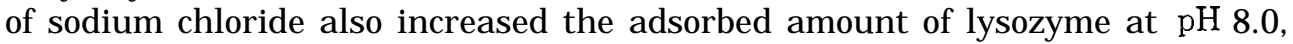
although much higher concntration of sodium chloride (above $1 \mathrm{M}$ ) was necessary to the saturation in the adsorbed amount.

\section{pH-Dependence of adsorption of lysozyme on chitin column}

The pH-dependence profile can be divided into three parts; first is below pH 5 , second is between pHs 5 and 8 and other is the region around a peak at pH 9 as shown in Fig. 8. In the previous experiment (Imoto et al., 1968), a limited amount of lysozyme was applied and pH-adsorption profile showed a plateau region from $\mathrm{pH} 6$ to $\mathrm{pH}$ 10. In the present experiment, a large excess of $1 \mathrm{y}$ sozyme was applied, and consequently two peaks were separated clearly in the region from $\mathrm{pH} 6$ to $\mathrm{pH}$ 10. The most strong adsorption was observed at $\mathrm{pH} 9$. It should be noted that in the presence of $0.5 \mathrm{M}$ sodium chloride, the adsorbed amount was not $\mathrm{pH}$-dependent in the range from $\mathrm{pH} 2$ to 8 . 


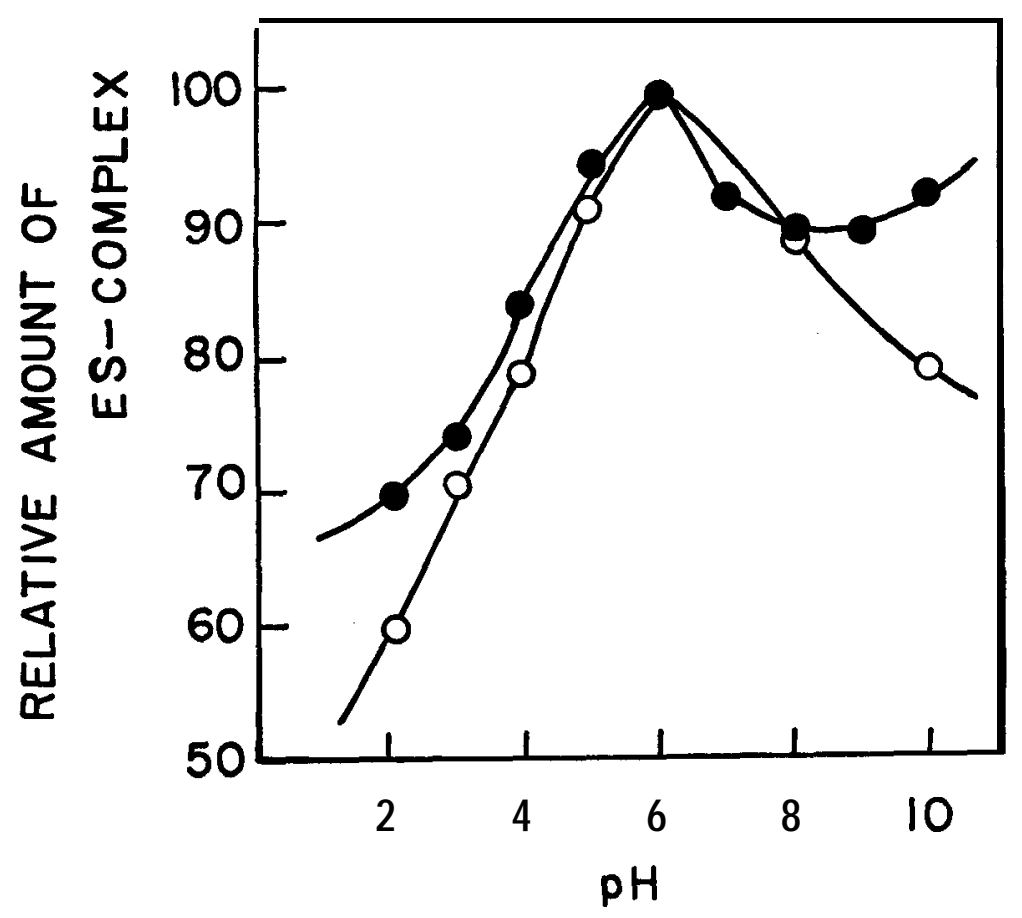

Fig. 6. pH-Dependence of formation of lysozyme-substrate complex. $\bigcirc$ :Carboxymethyl chitin and : hydrolyzed carboxymethyl chitin. Concentration of lysozyme and substrate was $0.1 \%$, respectively. Buffer solutions with constant ionic strength of 0.1 were used.

\section{DISCUSSION}

When Iysozyme solution (final concentration :0.1\%) was mixed with the excess amount of the substrate glycol chitin (final concentration: above $0.2 \%$ ) in $0.1 \mathrm{M}$ phosphate buffer solution at $\mathrm{pH} 5.6$, the most large value of $\Delta \mathrm{DD}_{293}$ was observed. This largest value reached to 0.11 , which was corresponding to the difference molar extinction coefficient of 1600 calculated on the basis of molar concentration of lysozyme in the mixture. This value is nearly two thirds of $\triangle \mathrm{OD}_{293}$ arisen from one tryptophan residue of a protein molecule in a denaturation blue-shift (Hamaguchi and Hayashi, 1972). This fact may mean that one tryptophan residue in average was buried by the substrate under condition mentioned above. If there were any other observed values of $\triangle \mathrm{OD}_{293}$ larger than 0.11 with lysozyme at final concentration of $\mathbf{0 . 1} \%$, there would be the formation of completely different type of the lysozyme-substrate complex. The presence of sodium chloride did not change the maximum value of $\triangle \mathrm{OD}_{293}$, though it changed the equilibrium constant for the complex formation. It is, therefore, concluded that lysozyme-substrate complex formed in the presence of sodium chloride was similar to those formed in an ordinary buffer solution, except for the difference in their fine structures. This easily presumed from the fact that 


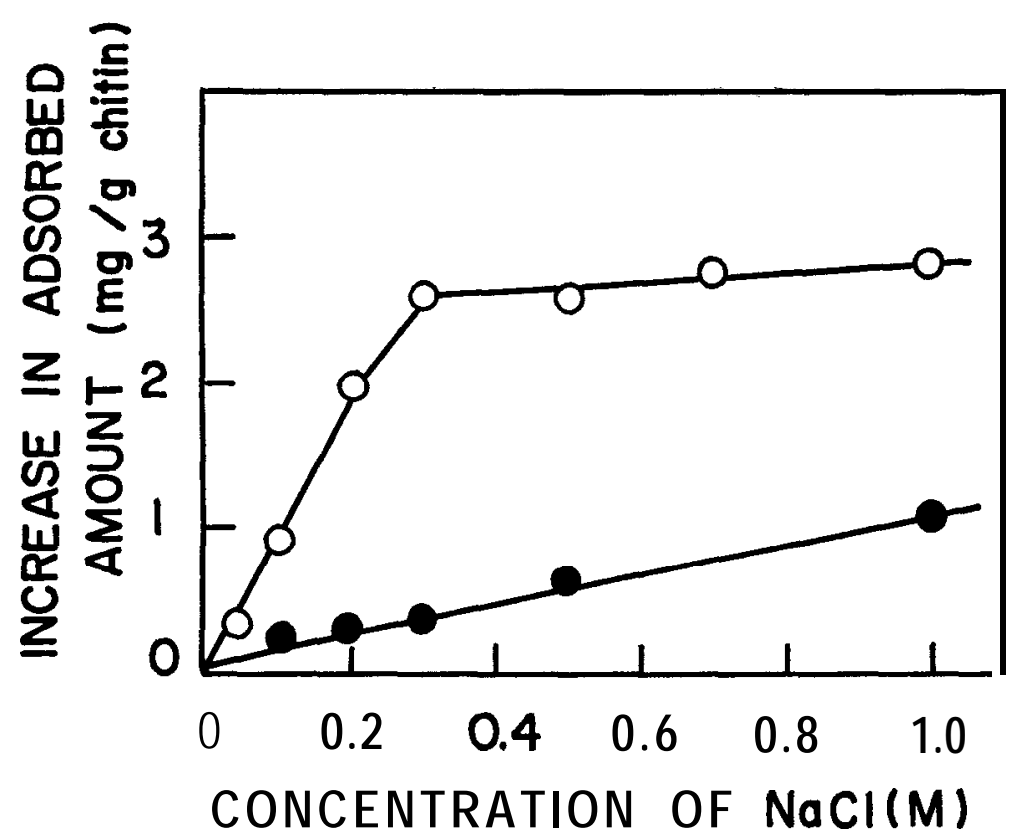

Fig. 7. Effect of sodium chloride on adsorbed amount of lysozyme on chitin column. $\bigcirc: 0.1 \mathrm{M}$ Acetate buffer at pH 4.0 and $\bigcirc \quad$ : $0.1 \mathrm{M}$ phosphate buffer at pH 8.0.

the complex formed in the presense of sodium chloride was difficult to hydrolyze and considered to be a sort of nonproductive complex. (Imoto et al., 1968).

The lysozyme-substrate complex formation measured by difference spectrophotometry did not show the $\mathrm{pH}$-dependence in the presence of enough amount of sodium chloride. The $\mathrm{pH}$-dependence of the complex formation may be reflection of change in the ionization state of side chain functional groups. The effect of sodium chloride seems, therefore, to appear via changes in the ionization state of the side chains. However, it is too large to explain by only the change in the ionization state as reported in a previous paper (Imoto et al., 1969). There must be another important factors through which the effect of sodium chloride would appear, though it is, at present time, not known.

It has been reported that monomer, dimer or tetramer of $\mathrm{N}$-acetylglucosamine showed a flat profile in the $\mathrm{pH}$-dependence of the complex formation with $1 \mathrm{y}$ sozyme and their complex formations were scarcely affected by the presence of sodium chloride (Rupley, 1967). There may be some correlation between the pHdependence and the effect of sodium chloride in the complex formation. In this connection, it may be noted that the maximum value of $\Delta\left(\Delta \mathrm{OD}_{293}\right)$ for oligosaccharide substrates (partially hydrolyzed substrates) was attained by a considerably higher concentration of sodium chloride than for polymer substrate (see Table 1).

It was reported that pH-dependence of adsorbed amount of lysozyme on a column of insoluble substrate showed only a plateau region, when a limited 


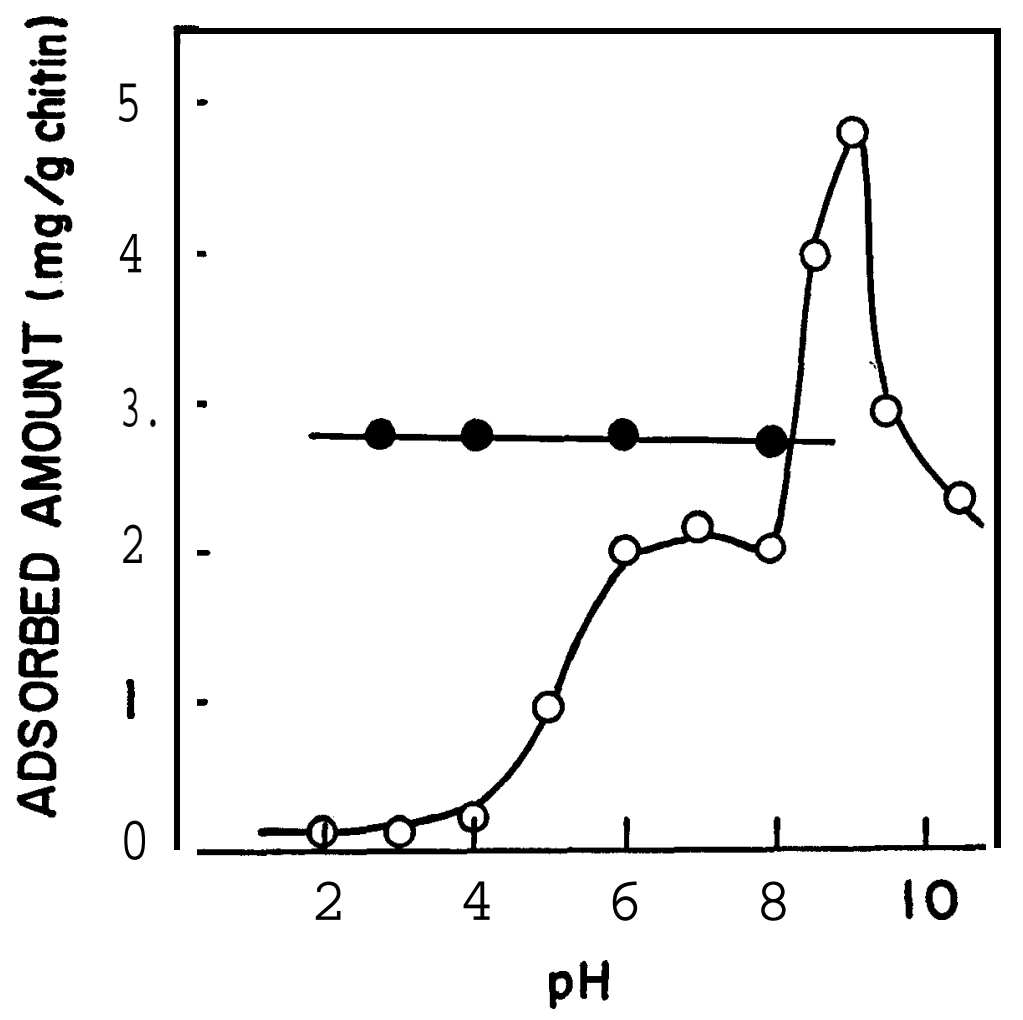

Fig. 8. pH-Dependence of adsorption of lysozyme on chitin column. $\bigcirc: 0.1 \mathrm{M}$ Buffer solution and $\bullet \quad: 0.1 \mathrm{M}$ buffer solution containing $0.5 \mathrm{M}$ sodium chloride.

amount of lysozyme was applied onto the column (Imoto et al., 1969). When an excess amount of lysozyme was applied, the $\mathrm{pH}$-adsorption profile showed a distinguished peak at $\mathrm{pH} 9$ together with the plateau region around $\mathrm{pH} 7$. Thus, there may be two types of the complex with lysozyme, which were not detectable in solution by difference spectrophotometry. The effect of sodium chloride on the adsorption of lysozyme was again confirmed below $\mathrm{pH} 8$ as reported previously. Above $\mathrm{pH} 9$, no effect of sodium chloride was observed.

Although the effects of sodium chloride on the formation of the various types of the lysozyme-substrate complex were thus demonstrated again, it is necessary to carry out the further experiments for elucidating the mechanism by which the effect of sodium chloride is brought about.

\section{REFERENCES}

Imoto, T., K. Hayashi and M. Funatsu. 1968 Characterization of Enzyme-substrate Complex of Lysozyme I. Two Types of Complex. J. Biochem., 64: 387

Imoto, T., K. Hayashi and M. Funatsu. 1969 Characterization of Enzyme-substrate Complex of Lysozyme II. Effects of pH and Salts. J. Biochem., 65: 667 
Hayashi, K., Fujimoto, M. Kugimiya and M. Funatsu. 1969 The Enzyme-Substrate Complex of Lysozyme with Chitin Derivatives. J. Biochem., 65: 401

Hayashi, K., T. Imoto and M. Funatsu 1964 The Enzyme-Substrate Complex of a Muramidase (Lysozyme) Catalyzed Reaction II. Evidence for Conformational Change in the Enzyme. J. Biochem., 55: 516

Imai, K., T. Takagi and T. Isemura. 1963 Recovery of Intact Structure of Muramidase (Lysozyme) after Reduction of All Disulfide Linkages in 8 M Urea. J. Biochem., 53: 1

Hamaguchi, K. and K. Hayashi. 1972 Protein. Kodansha, Tokyo

Rupley. J. A. 1967 The Binding and Cleavage by Lysozyme of N-Acetylglucosamine Oligosaccharides. Proc. Royal Soc., B 167 : 416 